\title{
Agro-ecological variability effects on an index- based insurance design for extreme events
}

\author{
Omar Valverde-Arias, Alberto Garrido, Antonio Saa-Requejo, \\ Francisco Carreño, Ana María Tarquis
}

\begin{abstract}
A B S T R A C T
Index-based insurance (IBI) is a risk transfer tool that is widely used in low-incomes countries, especially catered to smallholder farmers. A good correlation between the selected index (in this case Normalized Difference Vegetation Index -NDVI-) and the crop losses of the insured area is a key requirement for well-performing system. Usually, IBI application area is defined by political boundaries, despite that variation in soil, topography, and climate is more important. In this work, agro-ecological variability effects will be studied in the IBI context. The case study was the rice crop failure in Babahoyo canton (Ecuador), using NDVI as the crop damage indicator.

In a previous study, zones of similar soil, topographic and climatic characteristics (AHZs) were defined using principal component analysis in Babahoyo canton. Two largest AHZs were found in this canton. They were $f 7$ and $f 15$, which account for $91 \%$ of the total rice crop area in Babahoyo. We sampled reflectance values of red, blue, near infra-red (NIR) and medium infra-red (MIR) bands over bare soil (1st of January) by observation points, within $f 7$ and $f 15$. The reflectance band values were used to study whether the difference between the two AHZs could be appreciated through remote sensing. Then, we did the same but for NDVI average of the rice crop cycle, i.e., 15th of January to 15th of May (NDVI ave). It was done for confirming that the AHZs ( $f 7$ and $f 15$ ) have an influence over rice crop development. The used product was MODIS imagery (2001-2017).

We stratified the sampling through the AHZs, applying $30 \%$ density for ensuring the accuracy of the selected pixels. Statistically significant differences between the $f 7$ and $f 15$ zones were found in all the analysed reflectance bands and in NDVI_ave. This found supported the differences that the agro-ecological map pointed out in its database. At the same time, the NDVI ave distribution for each AHZ presented a statistically significant difference of the accumulated probability below the threshold $(0.4)$, which is confirmed as a reliable threshold for rice crop failure. This stratified sampling could improve the representativeness and accuracy of crop state assessments and reduce the basis risk.
\end{abstract}

\section{Introduction}

Hegerl et al. (2007) and Sivakumar et al. (2005) indicated that climate change has increased the variability and uncertainty of weather, making agricultural production more exposed to climatedriven risks. According to Trærup (2012), smallholder farmers of developing countries are not prepared to address this problem. Under this scenario, they would be in a weak position during the next cropping season, thereby compromising its continuity (Hellmuth et al., 2009).

Menand and Townsend (2010) claimed that agricultural insurance could be used efficiently for transferring agricultural-production risk from farmers to more qualified entities (insurance companies). Additionally, Skees et al. (2007) and Wright and Hewitt (1994) mentioned that agricultural insurance enables farmers to meet their credit commitments, improving their capacity to face an extreme event, and allowing them to continue and even stimulate their investment in 

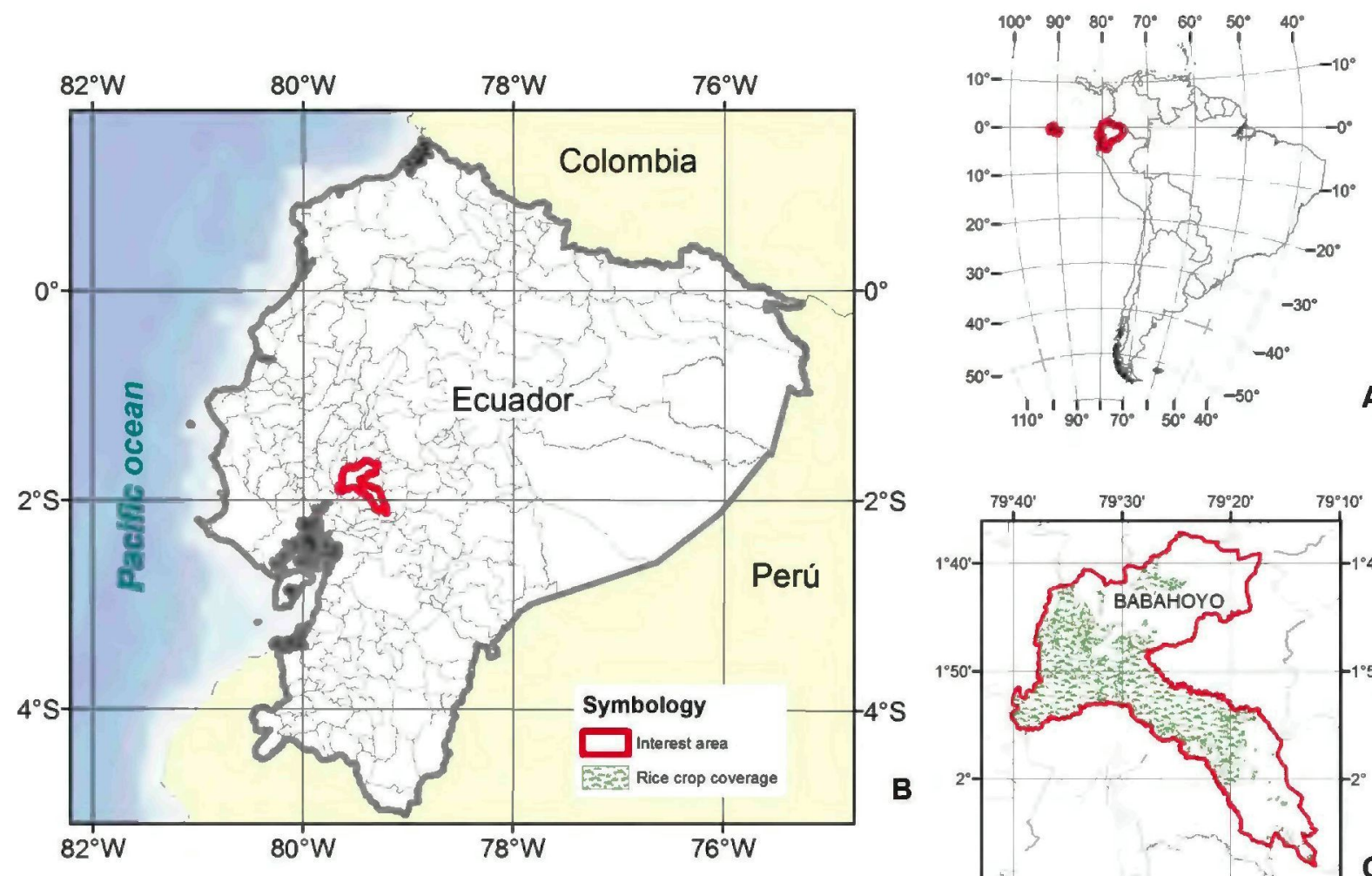

A

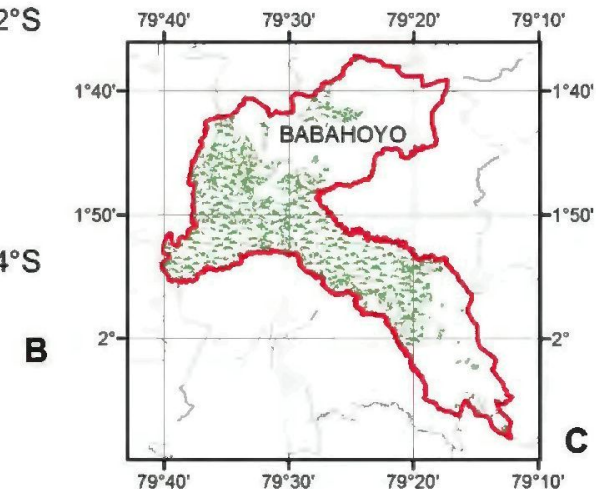

Fig. 1. A) Location of Ecuador in South America, B) location of Babahoyo canton in Ecuador, and C) Babahoyo canton with rice crop coverage.

agricultural production activities. It has been widely used throughout the world, particularly in low-income countries (Chantarat et al., 2007).

Conventional insurance requires an in situ verification of the reported losses, but index-based insurance (IBI) does not. This is a type of agricultural insurance that determines the crop damage caused by an extreme event through a highly correlated index (de Leeuw et al., 2014).

Barrett et al. (2008) pointed out that IBI has some advantages compared to conventional insurance. The administrative costs and consequently the premium cost are lower. Moreover, IBI can be applied over large and widespread areas. Thus, avoiding adverse selection (when only most risky farmers are insured), systemic risk (all associated risks of a system), and moral hazard (farmers neglect their crops because they are insured). On the contrary, IBI's main limitation is basis risk, which is the inherent risk related to an inaccurate correlation between an index measure and the real farmer's losses (Mobarak and Rosenzweig, 2013; Binswanger-Mkhize, 2012).

Basis risk can arise due to different situations. For example, when an insured farmer obtains a compensation despite having no losses. On the contrary, other farmer does not receive a compensation even though his crop has actually been hit. Clarke (2016) mentioned that basis risk could be increased when all insured farmers pay the same premium price, yet a group of them have significantly more losses than those of the others, i.e., the risk exposure status of insured farmers varies.

It is necessary to account for the variability of the area of insurance application for avoiding basis risk in IBI implementation (Stoppa and Hess, 2003; Hertzler, 2004). For this reason, White et al. (1992) claimed that effective crop condition monitoring is very desirable, and it must be based on a solid sampling and statistical design that allows one to estimate the status, trends, and conditions of the phenomena that affect crops.

We used NDVI as crop failure indicator, because, following Rulinda et al. (2012), the Normalized Difference Vegetation Index (NDVI) is the most widely used vegetation index, and it is based on the normalized difference of near infra-red (NIR) and red spectral reflectance (Pettorelli et al., 2005). The relationship of NDVI with vegetation state is well known. Moreover, it can also be used as crop state indicator, biomass estimator, and drought monitoring (Son et al., 2012; Subash et al., 2011 and $\mathrm{Gu}$ et al., 2007).

In the index-based insurance field, as is evidenced in the studies of Trangmar et al. (1986), Barraza (2012) and Mude et al. (2009), the standard methodology of NDVI sampling is determined by administrative regions and land use. Most studies have focused on climate as the main source of variability, leaving out the probable soil and topographic variability effect on index values.

Thus, it is very important to have information regarding also soil and topographic properties that could afford researchers a better explanation of vegetation index variation across the study area. Some soil and topographic properties cannot be easily amended through a similar management crop system, such as soil texture, structure, altitude, and slope; thereby, we have to consider them. Many authors like Cambardella et al. (1994) and Letey (1985) have found that soil and topographic variables jointly with climate have an important effect on crop conditions, which will be estimate through NDVI values (Gu et al., 2007).

This study was performed in the context of an IBI implementation assessment in Babahoyo canton, Ecuador. This insurance design attempts to reduce basis risk through a proper discrimination of insurance influence area (IIA) variability produced by the interaction of soil, topography (slope, altitude), crop, and climate. IIA is a region where a determined index is representative. In this case, we have used agroecological homogeneous zones (AHZs) for determining IIA. AHZs aggregated zones with similar soil, topographic, and climatic characteristics; they were generated by principal component analysis in a previous study of Arias et al. (2018).

Our proposed IBI design will use NDVI as occurrence indicator of extreme events; in this case, they are drought and flood, which are the most frequent and largest events susceptible to be detected through 
NDVI. A completed evaluation of drought hazard in Babahoyo canton is presented in Arias et al. (2018) work.

For this reason, this paper aims to design an efficient stratified NDVI sampling. Considering the soil, topographic, and climatic variability found in the study area that could reduce basis risk of an eventual IBI design, as well as using an adequate sampling density. The stratification criterion was based on AHZs map.

\section{Materials and methods}

\subsection{Location of study area}

The study area is located in Ecuador (Fig. 1 A), in Babahoyo canton, see Fig. 1 B. Its area is 109,391 ha out which 102,517 ha correspond to agricultural lands. The study is focused on rice crop (Fig. $1 \mathrm{C}$ ), this crop is the most cultivated (46,556 ha) in Babahoyo (IEE, 2009), reaching $45 \%$ cultivated area of the canton (MAGAP, 2014).

\subsection{Cartographic data}

\subsubsection{Agro-ecological homogeneous zones map}

This map was generated by (Arias et al., 2018), it grouped similar soil, topographic, and climatic characteristics in agro-ecological homogeneous zones (AHZs) through principal components analysis in the Ecuadorian Coastal region (Fig. 2 A).

\subsubsection{Rice-cultivated land in Babahoyo canton $(1: 25,000)$}

The map of rice cultivated area for 2014 in Babahoyo canton (Fig. 2 C) was generated through pixels' supervised classification on high spatial resolution images (RapidEye), which have a spatial resolution of $5 \times 5$ m per pixel (MAGAP, 2014). In this canton, rice crop is periodi-cally cultivated over consolidated areas seldom varying year by year. Some of the areas present an irrigation structure that farmers could use
Table 1

Technical characteristics of imagery set (MODIS MOD13Q1V6). Adapted from (Didan, 2015).

\begin{tabular}{lc}
\hline Characteristic & Description \\
\hline Temporal granularity & 16 -day \\
Temporal extent & $2001-2017$ \\
Spatial extent & Ecuador \\
Coordinate system & Projected to Universal Transverse \\
& Mercator \\
Datum & WGS 1984 Zone $17 \mathrm{~S}$ \\
File format & HDF-EOS \\
Geographic dimensions & $1200 \mathrm{~km} \times 1200 \mathrm{~km}$ \\
Number of science dataset (SDS) & 12 \\
$\quad$ layers & 4800 rows $\times 4800 \mathrm{cols}$ \\
Rows/columns & $250 \mathrm{~m}$ \\
Pixel size &
\end{tabular}

as a support labour after the rainy season. However, the water used for it dependents on the precipitation and drought events are reported from these areas.

\subsubsection{Data from satellite imagery}

The product downloaded (NASA LP DAAC, 2015) and used was MODIS MOD13Q1V6 which has the following characteristics, see Table 1.

We used composite images ( 16 days) corresponding to the rice crop cycle (January 15th to May 15th) from 2001 to 2017, totalling 170 images. The rice crop cycle in Ecuador lasts about 120 days.

The HDF (Hierarchical Data Format) is a multilayer file, which includes twelve layers (Didan, 2015). The following layers were used in this study:

Hdf:0, pixel values in this layer correspond to NDVI. The total

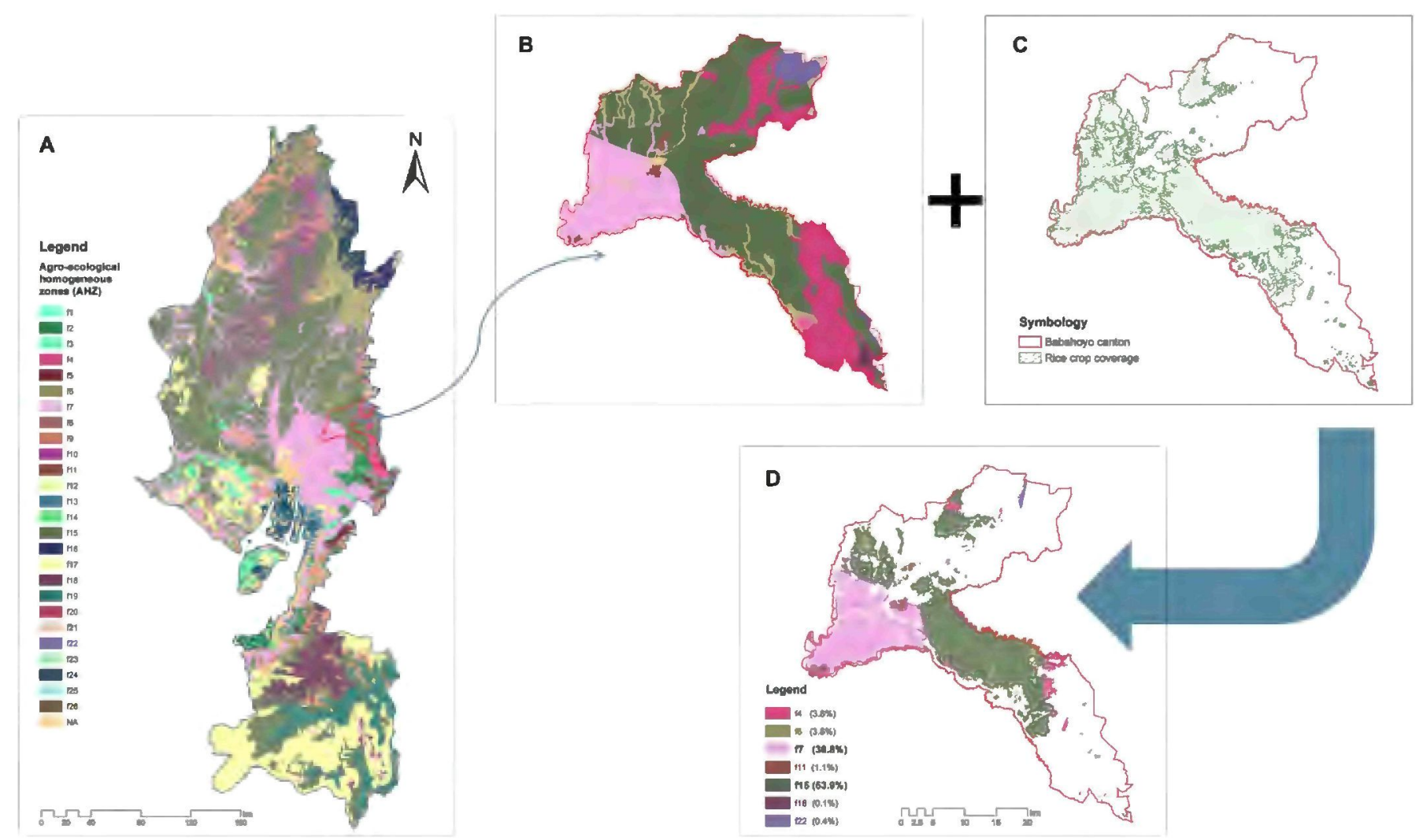

Fig. 2. A) Agro-ecological homogeneous zones (AHZs) map from (Arias et al., 2018); B) AHZs in Babahoyo canton, C) rice crop coverage, and D) AHZs on rice cultivation area in Babahoyo canton. 
imagery set was used (170 images), as well as two NDVI images for each rice crop cycle month along 2001-2017.

Hdf:3, pixels values in this layer corresponds to surface reflectance band 1 (red), was used only the January 1st (2001-2017) observation, totalling 17 images.

Hdf:4, pixels values in this layer corresponds to surface reflectance band 2 (NIR), of which only the image of January 1st (2001-2017) was used, totalling 17 images.

Hdf:5, pixels values in this layer corresponds to surface reflectance band 3 (blue), of which only the image of January 1st (2001-2017) was used, totalling 17 images.

Hdf:6, pixels values in this layer corresponds to surface reflectance band 7 (medium infra-red MIR), of which only the image of January 1st (2001-2017) was used, totalling 17 images.

\subsection{Bare soil and NDVI sampling methodology}

The first criterion of stratification was an AHZs map (Arias et al., 2018 ) as seen in Fig. 2 A, which overlies (using overly ArcGIS tool Identity) the Babahoyo canton boundary, resulting the agro-ecological homogeneous zones of Babahoyo canton (Fig. 2 B). Then, this map was overlain with rice crop coverage (Fig. 2 C) to obtain AHZs within rice cultivation in Babahoyo canton (Fig. 2 D). The most representative AHZs found within the rice crop coverage were selected ( $f 7$ and $f 15$ ) see Fig. 3 A. The main differences between these two AHZs are related to
Table 2

Topographic, soil and climatic characteristics of agro-ecological homogeneous zones (AHZs) in Babahoyo canton.

\begin{tabular}{lcc}
\hline AHZs characteristics & $f 7$ & $f 15$ \\
\hline Slope & $0-5 \%$ & $5-12 \%$ \\
Altitude & $1-12 \mathrm{~m}$ & $>12-35 \mathrm{~m}$ \\
Clay & $>50 \%$ & $35-50 \%$ \\
Effective depth & $50-100 \mathrm{~cm}$ & $>100 \mathrm{~cm}$ \\
$\mathrm{pH}$ & $5.6-6.5$ & $6.6-7.4$ \\
Organic matter & $2-4 \%$ & $2-4 \%$ \\
Temperature & $24-25^{\circ} \mathrm{C}$ & $24-25^{\circ} \mathrm{C}$ \\
Precipitation & $500-700 \mathrm{~mm}$ & $700-900 \mathrm{~mm}$ \\
Soil Classification & Typic hapluderts & Vertic eutrudepts
\end{tabular}

* According to USDA Soil Taxonomy (Soil Survey Staff, 2014).

soil and topographic characteristics, particularly their water retention capacity (Arias et al., 2018). The former step is the improvement of the standard methodology because it considered the agro-ecological characteristics (soil, topography and climate), analysed their joint interaction with land use (rice crop coverage), and political boundary, facing an extreme event.

Based on AHZs ( $f 7$ and $f 15$ ), a random points shapefile (RPS) was generated using an ArcGIS tool, fulfilling the following conditions:

a) Avoiding the border effect by eliminating the observation points, which were within the first $80 \mathrm{~m}$ from the border. b) Covering at least

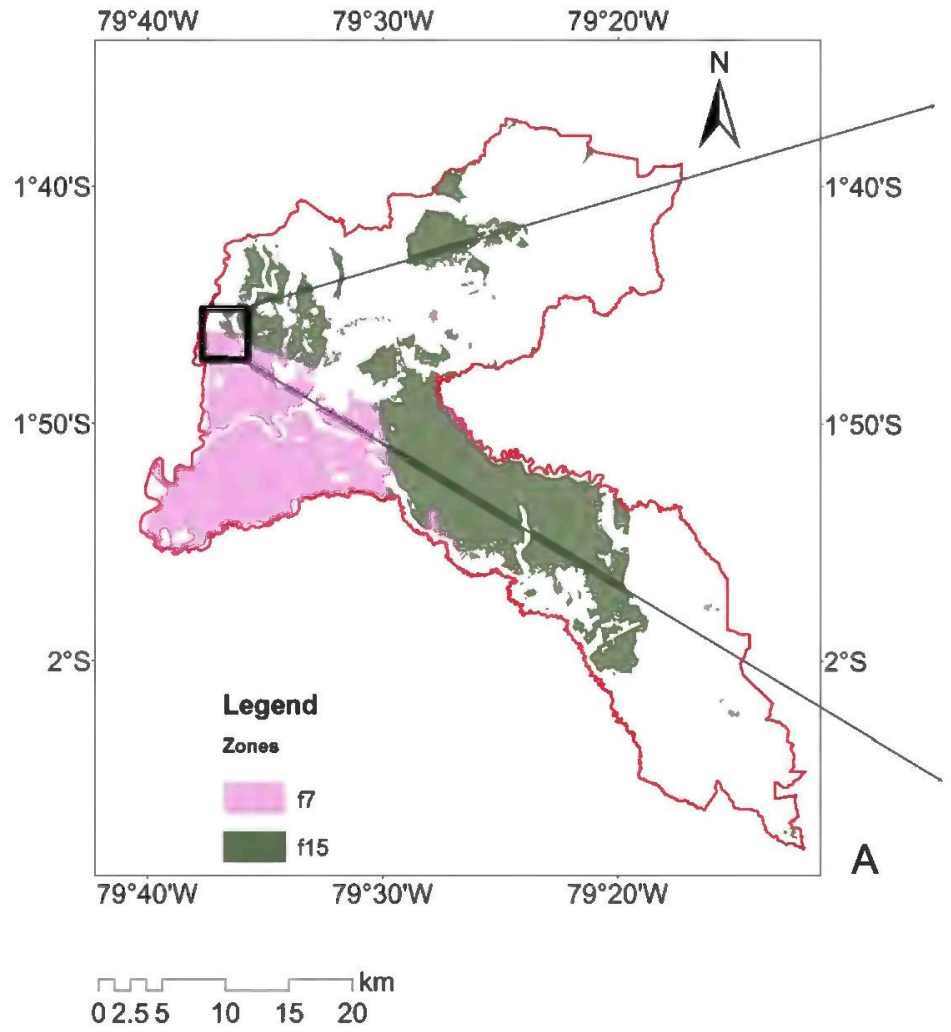

$02.55 \quad 10 \quad 15 \quad 20$

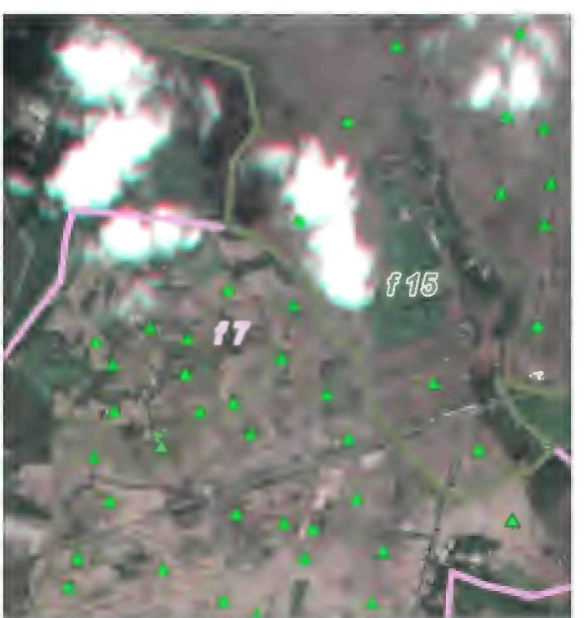

B

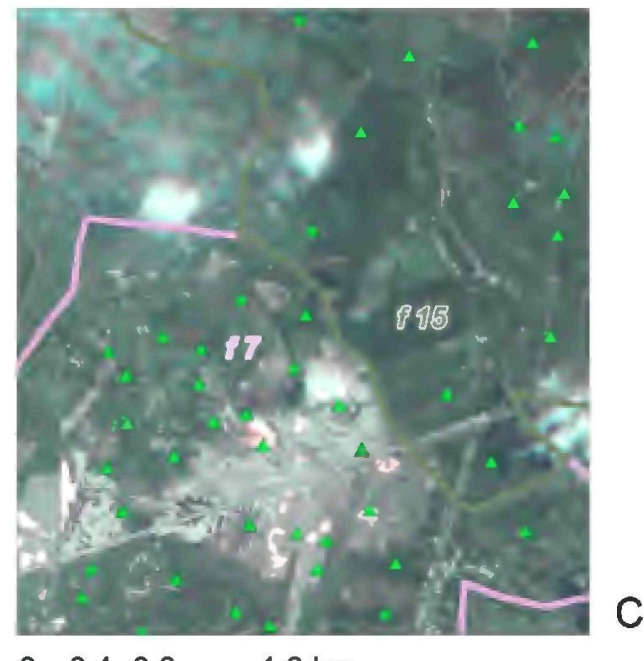

$\begin{array}{llll}0 & 0.4 & 0.8 & 1.6 \mathrm{~km}\end{array}$

Fig. 3. High spatial resolution images RapidEye of study area portion (represented by black rectangle in A) and sampling random points of: B) bare soil prepared for rice sowing at January 13th, 2014 and C) rice cultivation affected by flood at March 29th, 2012 both inside of AHZs f7 and f15. 
Table 3

Descriptive statistics of bare soil reflectance bands (red, NIR, blue and MIR) and NDVI_ave of rice crop cycle.

\begin{tabular}{|c|c|c|c|c|c|}
\hline & \multicolumn{4}{|c|}{ Reflectance } & \multirow{3}{*}{$\begin{array}{l}\text { NDVI_ave } \\
\text { Rice crop cycle } \\
\text {-(January 15th-May } \\
\text { 15th) }\end{array}$} \\
\hline & Red & NIR & Blue & MIR & \\
\hline & \multicolumn{4}{|c|}{ Bare soil (January 1st) } & \\
\hline Mean & 0.285 & 0.368 & 0.244 & 0.231 & 0.468 \\
\hline Typical error & 0.001 & 0.001 & 0.001 & 0.001 & 0.001 \\
\hline Median & 0.283 & 0.374 & 0.255 & 0.229 & 0.487 \\
\hline $\begin{array}{l}\text { Standard } \\
\text { deviation }\end{array}$ & 0.102 & 0.108 & 0.105 & 0.076 & 0.116 \\
\hline Kurtosis & 1.866 & 1.158 & -0.130 & -0.056 & 0.559 \\
\hline Skewness & 0.555 & 0.222 & -0.060 & 0.154 & -0.785 \\
\hline Count & 6213 & 6213 & 6213 & 6213 & 31,756 \\
\hline
\end{tabular}

Table 4

ANOVA for agro-ecological homogeneous zones (AHZs) of bare soil reflectance bands (red, NIR, blue and MIR).

\begin{tabular}{lccccc}
\hline Source & Square sum & F.D. & Mean square & F-ratio & P-value \\
\hline Red & & & & & \\
Inter-AHZ & 0.27 & 1 & 0.27 & 25.58 & 0.000 \\
Intra-AHZ & 64.92 & 6211 & 0.011 & & \\
Total (corrected) & 65.19 & 6212 & & & \\
NIR & & & & & \\
Inter-AHZ & 0.73 & 1 & 0.73 & 6.000 \\
Intra-AHZ & 71.61 & 6211 & 0.012 & & \\
Total (corrected) & 72.34 & 6212 & & & \\
Blue & & & & & \\
Inter-AHZ & 0.59 & 1 & 0.59 & 54.09 & $\mathbf{0 . 0 0 0}$ \\
Intra-AHZ & 67.88 & 6211 & 0.011 & & \\
Total (corrected) & 68.47 & 6212 & & & \\
MIR & & & & & \\
Inter-AHZ & 0.054 & 1 & 0.05 & 9.49 & $\mathbf{0 . 0 0 2 1}$ \\
Intra-AHZ & 35.63 & 6211 & 0.0057 & & \\
Total (corrected) & 35.68 & 6212 & & & \\
\hline
\end{tabular}

Italic and bold represent significant statistical difference.

$30 \%$ of the study area, and c) avoiding sampling the same pixel by imposing a minimal distance among points. As each pixel represents $250 \times 250 \mathrm{~m}$, the diagonal $(\mathrm{D}=353.55 \mathrm{~m})$ plus $1 \mathrm{~m}$ was chosen as the minimal distance among sample points.

The NDVI and reflectance (red, blue, NIR and MIR) pixel values were extracted by RPS. The selected pixels of the red, blue, NIR and MIR bands correspond to January1st (2001-2017); and NDVI pixel values correspond to images during the rice crop cycle (January 15th to May 15th) in the same period. The quality of the extracted pixels were tested through the quality layer (Didan, 2015); this layer has a quality indicator (Rank key) for each pixel of both NDVI and reflectance (red, blue, NIR and MIR) layers. When a pixel has the Rank key $=0$, it indicates that this pixel has high quality and that we can use it with confidence. Thus, we eliminated all pixels with Rank key different to $O$, see user guide of Didan et al. (2015).

Only the images of January 1st (from 2001 to 2017) were used; because, it is the time of the year where we can find bare soil, as consequence of land's preparation for the rice sowing (Cabangon and Tuong, 2000; Moreno, 2014). This is clearly observed in the high spatial resolution image $(5 \times 5 \mathrm{~m})$ shown in Fig. $3 \mathrm{~B}$. To ensure that sampling pixels were representative of bare soil, only the observations of red, blue, NIR and MIR that have the corresponding NDVI values $<0.2$ were used because a higher value could correspond to vegetation coverage.

Barnes and Baker (2000) and Gomez et al. (2008) indicated that remote sensing has been used successfully for many years in mapping soil properties. For this reason, reflectance values from the imagery set of red, blue, NIR and MIR layers in each representative AHZ were sampled. These bands were included in the analysis, as some soil properties are better determined using the visible spectrum (blue and red), while other properties are better determined using the near and medium infra-red spectrum (Viscarra Rossel et al., 2006).

In Addition, NDVI values during the rice crop cycle were sampled as it was mentioned previously. In this manner, we can study whether the differences between the AHZs are statistically significant for the NDVI values. In this case, stratification could be used for differencing premium cost in each AHZ in an eventual IBI design. In other words, a calculation of rice crop lost probability should be applied for each AHZ, but not at cantonal level. This could make the IBI sustainable in time and more attractive to farmers.

\subsection{Rice-yield estimation}

An NDVI_ave threshold of 0.4 , for crop failure, was calculated by Valverde-Arias et al., 2018 for rice crops in the same study area (Babahoyo). The researchers calculated this threshold based on the work of Gu et al. (2007) and Rulinda et al. (2012), characterizing the most affected years of extreme climatic events from 2001 to 2014. The value of 0.4 was the NDVI_ave mean of those years, which were affected by drought and floods. Via yield estimation, we wanted to verify if this threshold is a reliable value and representative of an economic failure for rice producers. We did not use a threshold for a particular phenological stage of the rice crop cycle. Because, some short-duration extreme events could be overcome by the crop. Therefore, it is more convenient to wait for the end of crop season to quantify the affectation.

Since 2014, the General Coordination of the National Information System (CGSIN-acronym in Spanish-) of Ecuadorian Agricultural and Livestock Ministry (MAG -acronym in Spanish-) has conducted a riceyield estimation project, in which they have gathered yield samples across mapped rice areas. In consequence, 369 georeferenced rice-yield observations ( $\mathrm{t} / \mathrm{ha}$ ), for 2014-2017 rainfed cycles (January to May) in Babahoyo canton over AHZs $f 7$ and $f 15$, were available. These rice-yield observations were correlated with their corresponding spatial and temporal NDVI_ave values, obtaining a rice-yield estimation model. Huang et al. (2013), Quarmby et al. (1993) and Son et al. (2014) have also generated rice-yield estimation models based on NDVI values.

\subsection{Statistical analysis of bare soil and NDVI}

First, a statistical descriptive analysis was conducted to test the normality of the data set. Then, an analysis of variance (ANOVA) was applied, in which the variability factor was the AHZs, for a data set of bare soil reflectance (red, blue, NIR and MIR bands). ANOVA for NDVI_ave, AHZs and time (years) were the variability factors. The least significant difference test of Fisher (Williams and Abdi, 2010) was performed to determine the degree of significance of the differences in the variability factors.

For the first data set (red, blue, NIR and MIR bands), we used the January 1st image during the period 2001-2017. These values are expressed in percentage ratios with values of from 0 to 1 . For the second data set, we used an NDVI average (NDVI_ave) of the rice crop cycle (January 15 th to May 15th) during the same years. This study started with a sampling density of $30 \%$ to assess the differences between the AHZs. For determining the minimal sampling density that allows one to discriminate the mentioned differences between AHZs, but conserving the sampling representativeness and accuracy. We also tested 5, 10, 15, 20 and $25 \%$ sampling densities in the same imagery data set. Then, we performed an ANOVA in which the variability factors were the sampling densities and AHZs. This analysis has allowed us to suggest an accurate sampling density that could be more adequate for practical purposes in IBI design. 


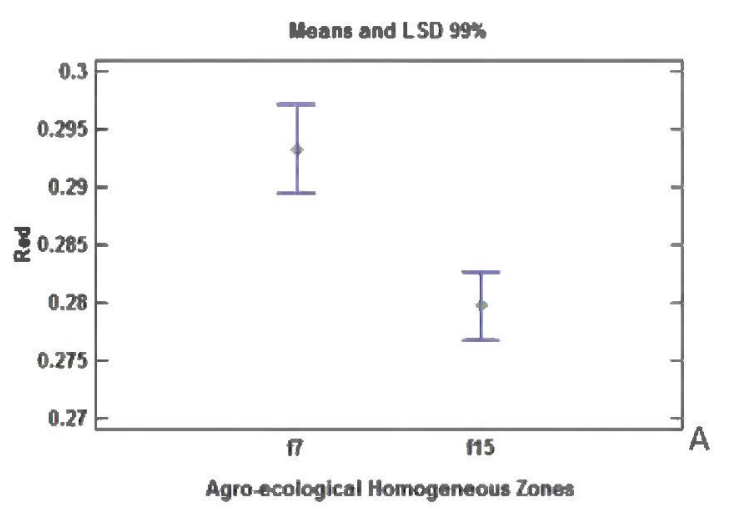

Means and LSD 99\%

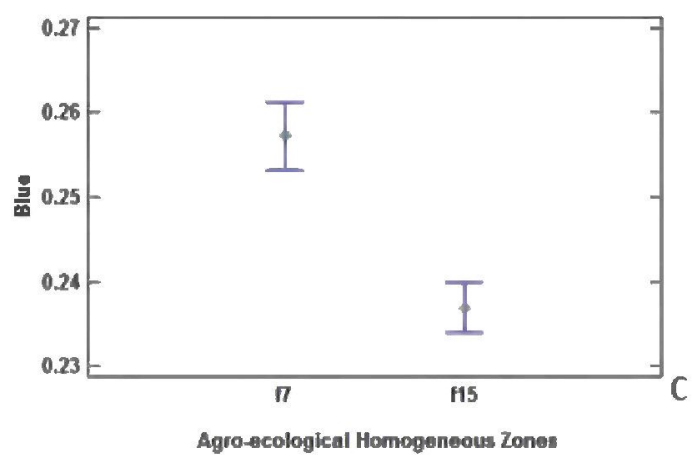

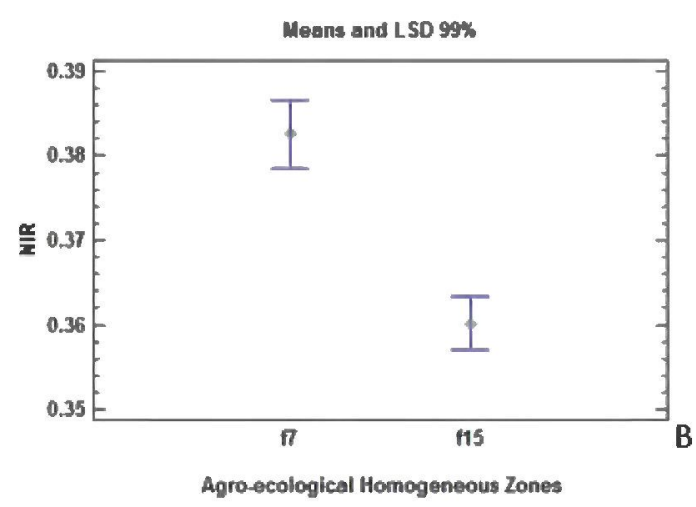

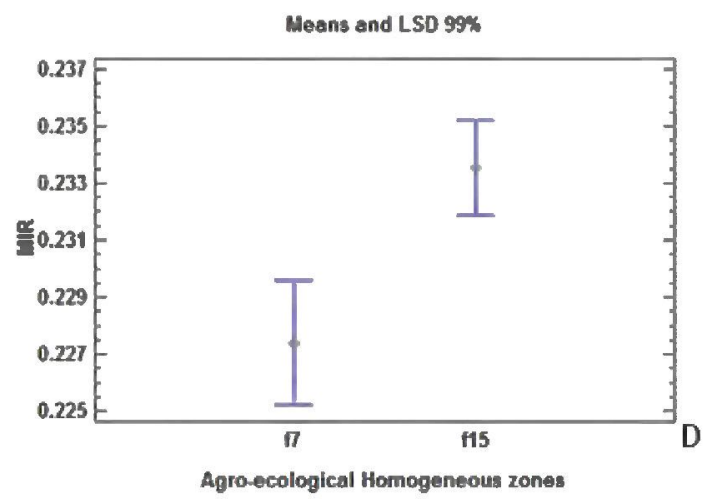

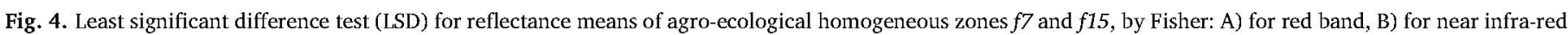
band NIR, C) for blue band, and D) for medium infra-red MIR.

Table 5

ANOVA of NDVI_ave for agro-ecological homogeneous zones (AHZs) $f 7$ and $f 15$.

\begin{tabular}{lccccc}
\hline Source & Sum of squares & F.D. & Mean square & F-Ratio & P-value \\
\hline Main effects & & & & & \\
A:AHZ & 6.40 & 1 & 6.40 & 663.1 & 0.000 \\
B:years & 108.35 & 16 & 6.77 & 701.35 & 0.000 \\
Iterations & & & & & \\
AB & 15.083 & 16 & 0.94 & 97.63 & 0.000 \\
Residues & 306.30 & 31,722 & 0.0097 & & \\
Total (corrected) & 429.82 & 31,755 & & & \\
\hline
\end{tabular}

Italic and bold represent significant statistical difference.

\subsection{Effect of agro-ecological variability on failure probability in a rice crop}

In the case that the NDVI_ave of both AHZs ( $f 7$ and $f 15$ ) are significantly different, the risk status of each AHZ was calculated. This consisted in determining the percentage of the NDVI_ave observations bellow the occurrence threshold (0.4) for each AHZ. After that, these two percentages were evaluated via a $Z$-test (Polasek, 2013). If the $\mathrm{Z}$ is outside of the critical rate range $\left(Z \leq z_{0.025}=-1.96\right.$ and $Z \geq z_{0.975}=1.96$ ), the two percentages are significantly different from each other.

\section{Results and discussion}

\subsection{Representative agro-ecological homogeneous zones}

In the Babahoyo canton over rice crop coverage, we have found seven AHZs. The most representative being $f 7$ with 17,110 ha and $f 15$ with 24,676 ha. These two zones accounted for $91 \%$ of the study area, as seen in Fig. 2 D.
As shown in Table 2, the most important agro-ecological differences between zones $f 7$ and $f 15$ are slope, altitude, texture, and effective depth as well as precipitation.

\subsection{Statistical analysis of soil variability}

Checking over the descriptive statistics (Table 3), skewness and kurtosis values were $<2.0$ indicating possible normality for datasets of reflectance and NDVI_ave, allowing us to continue with the analysis of variance.

As listed in Table 4, the reflectance of bare soil for the red, blue, NIR, and MIR bands is significantly different between zones $f 7$ and $f 15$. This could be due to the different soil characteristics of each zone. According to Thomasson et al. (2001), soil properties, such as texture, mineralogy, organic matter, and soil moisture, can be discriminated using remote sensing.

The reflectance is lower with higher the soil moisture in soils with low humidity; for example, those in the study area at the beginning of the rainy season (Weidong et al., 2002). For the red, NIR and blue bands, the reflectance is lower in zone $f 15$ than that in $f 7$ (Fig. $4 \mathrm{~A}, \mathrm{~B}, \mathrm{C}$ ) which is in agreement with Table 2. The AHZ $f 15$ is in a higher precipitation zone (700-900 mm annually) than that of $f 7(500-700 \mathrm{~mm}$ annually); thus, $f 15$ could have higher soil moisture content. On the other hand, the dynamics of water availability in each zone during the rice crop cycle is complex, influencing other factors. The slope and texture of the soil of $f 7$ could provide better conditions for retaining water as the soil has finer texture and it is flatter than that of $f 15$. As seen in Fig. 3 C (RapidEye scene of March 2012) during a year with excessive precipitation, zone $f 7$ presents some flooded areas, while zone $f 15$ does not show any trace of poor drainage.

The reflectance of NIR (Fig. 4 B) in $f 7(0.38)$ corresponds to a clay soil, according to Thomasson et al. (2001); $f 15$ has a reflectance of 0.36 , 

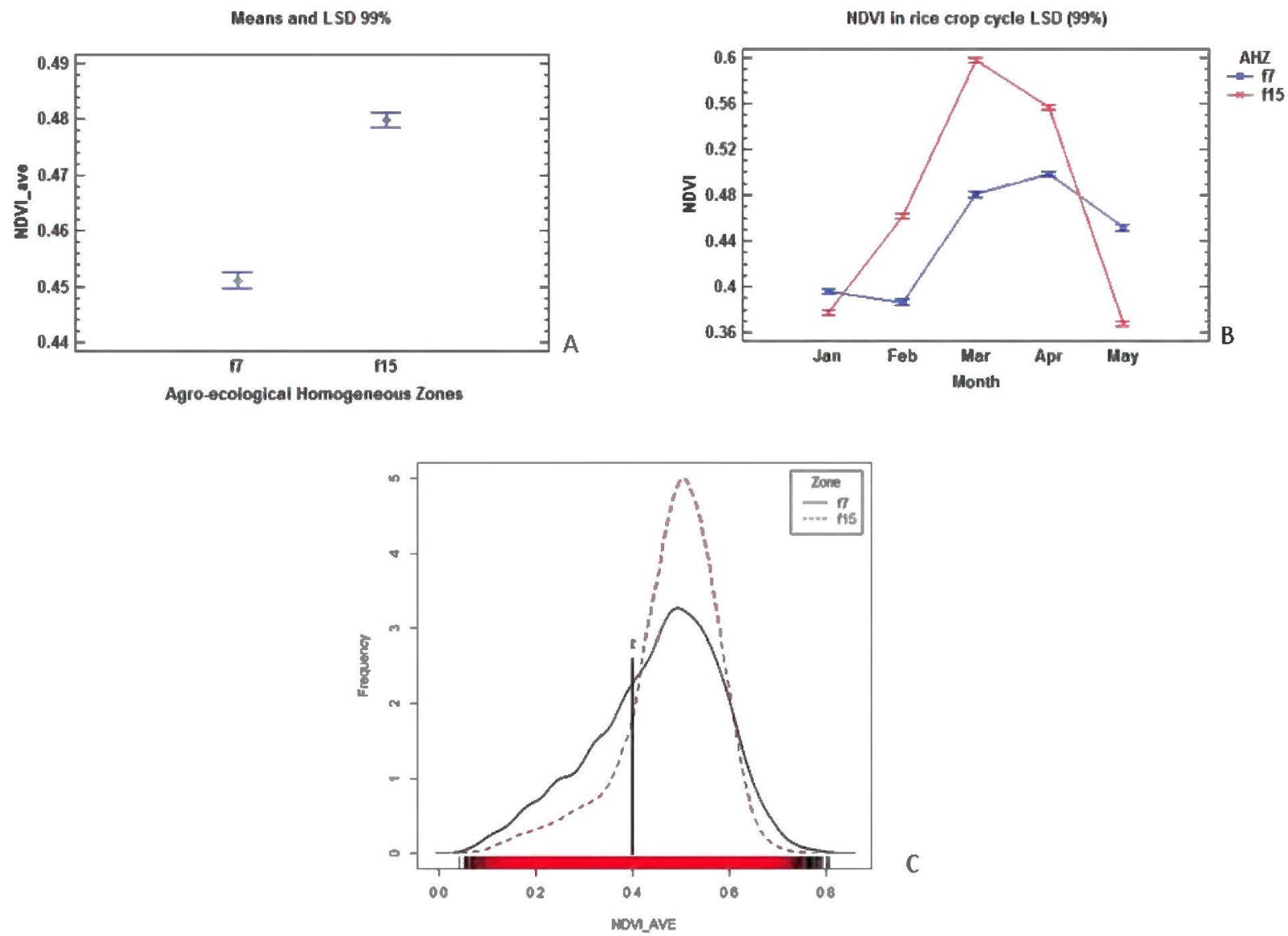

C

Fig. 5. A) Multiple rank test (LSD) for NDVI ave means of agro-ecological homogeneous zones (AHZs) $f 7$ and $f 15$; B) NDVI average distribution along rice crop cycle for AHZs $f 7$ and $f 15$ zones; and C) histograms of NDVI_ave data in analysed period (2001-2017) in Babahoyo for $f 7$ and $f 15$, $(t)$ drought affectation threshold $(0.4)$.

which indicates slightly lower clay content. This difference is in agreement with the soil characteristics (Table 2) and with the statement that a finer soil texture has greater reflectance (Mouazen et al., 2005).

Gomez et al. (2008) used MIR to determine soil organic carbon (SOC) content and found that values $<1 \%$ of SOC are not accurately discriminated. Along the same line, Henderson et al. (1992) mentioned that the reflectance percentage decreases when organic matter content increases. The AHZs $f 7$ and $f 15$ are in the same range of soil organic matter $(2-4 \%)$, which correspond to moderate organic matter content (Krishnan et al., 1980). However, the MIR reflectance is significantly different between AHZs $f 7(0.234)$ and $f 15(0.227)$, which indicates that $f 7$ has more organic matter content than that of $f 15$ (Fig. 4 D).

\subsection{Statistical analysis of NDVI}

As seen in Table 5, both variability factors (AHZs and years) and their interaction have a significant effect on NDVI_ave, with a confidence level of $99 \%$ and $p$-values of $<0.01$.

According to a multiple rank test of $99 \%$ LSD (Fig. 5 A), the NDVI_ave mean for a rice crop cycle of $f 7(0.45)$ is significantly different to that of $f 15(0.48)$, showing that the variability found between these zones over bare soil also persists on rice cultivation.

The variation regime of NDVI during the rice crop cycles of $f 7$ and $f 15$ analysed for the period is also different (Fig. 5 B). In f15, due mainly to favourable soil conditions for rice crop. There is a NDVI increase from 15th January (at sowing) until March when the crop has reached its maturity (flowering). Then, it diminishes during April and May during the rice's senescence. Meanwhile, the NDVI in $f 7$ follows a similar pattern but present lower values compared to $f 15$. As seen in Fig. $5 \mathrm{~B}$, the growth of rice in $f 7$ is limited by soil conditions both for the crop's development, and during the time that it takes to reach maturity at April. It is one month later than that of $f 15$ (May).

\subsection{Rice-yield versus NDVI}

The observed rice-yield was plotted versus NDVI_ave of the rice crop cycle (see Fig. 6). A normal accumulative curve was adjusted (Eq. (1) in Fig. 6) to relate both variables. The RMSE (\%) of 3.3 and an $R^{2}$ of 0.71 indicate a robust model. This type of curve was selected, instead of a linear regression to take into account the high values of the NDVI saturation effect on plant biomass (Gu et al., 2013) and the soil saturation effect on low NDVI values (Rondeaux et al., 1996). The correlation coefficient of observed versus estimated rice-yield was high (0.89), indicating that NDVI_ave is an adequate indicator that can be used for assessing catastrophic crop effects. This adequate correlation is evidenced in Table 7; where, they were matched NDVI_ave values with their corresponding historical rice-yields (from Survey of Surface and Continuous Agricultural Production -ESPAC acronym in Spanish-) in Babahoyo canton. This indicated us a suitable sensibility of NDVI_ave for determining rice-yield reduction in years affected by extreme climatic events (drought and flood).

We consider an extreme-event impact as catastrophic when riceyield is not plenty for farmers to make a profit. The national rice-yield average is approximately $4.2 \mathrm{t} / \mathrm{ha}$ and $5.7 \mathrm{t} / \mathrm{ha}$ in Babahoyo canton. Introducing an NDVI_ave of 0.4 in Eq. (1), a yield of $2.6 \mathrm{t} / \mathrm{ha}$ was obtained. This result is $<50 \%$ of the regional average. Moreover, a comparison between $f 7$ 's, $f 15$ 's, and cantonal's expected yields with the threshold's yield, is shown in Table 6 . This confirms that the NDVI_ave threshold of 0.4 (Valverde-Arias et al., 2018) is a reasonable value to be used under a catastrophic scenario. 


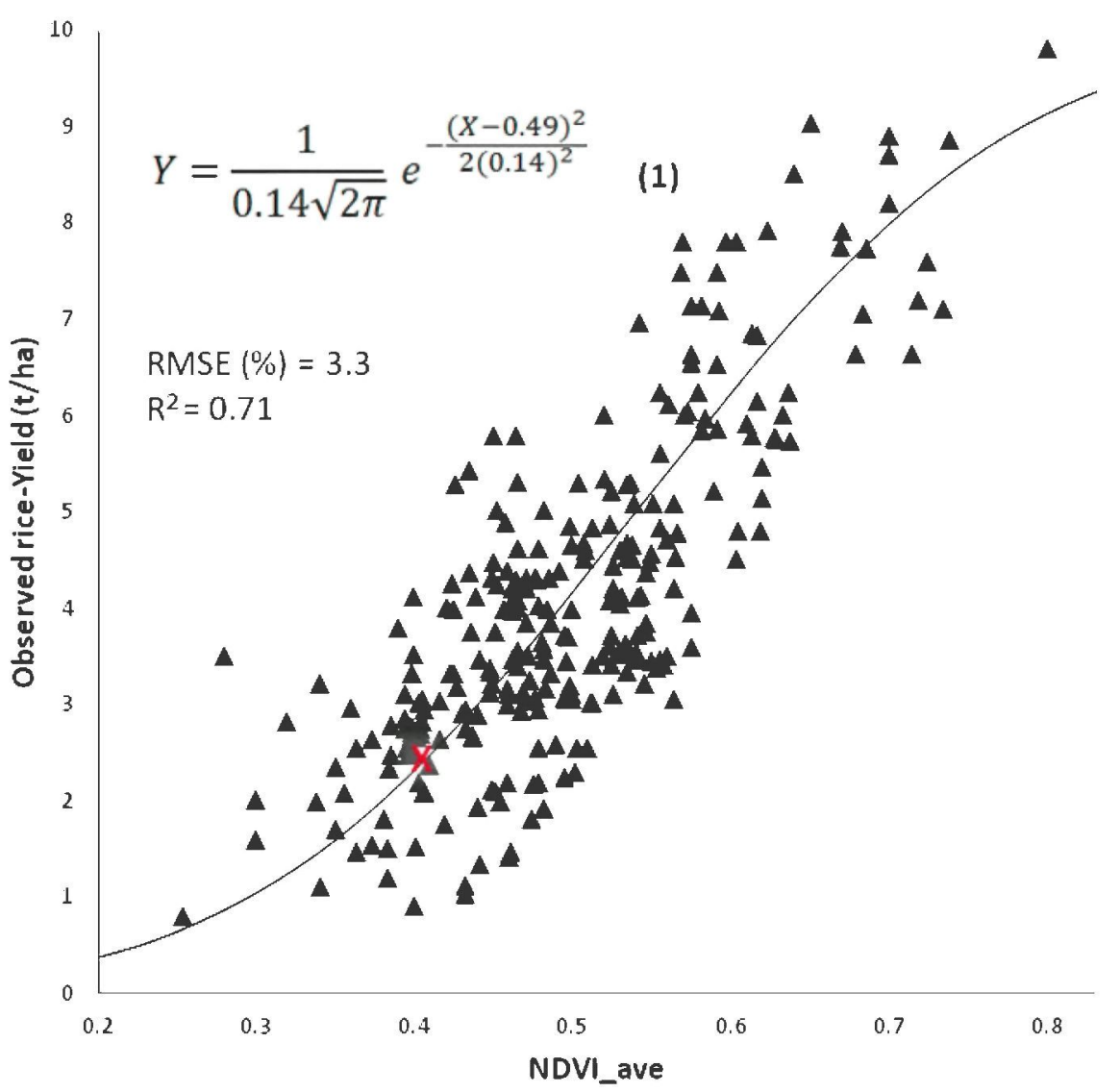

Fig. 6. Scatter plot of observed rice-yield and NDVI ave. Eq. [1] is a normal accumulative curve of crop yield in function of NDVI ave. Red point marks the NDVI ave threshold of crop failure $(0.4)$ and the correspond yield $(2.6 \mathrm{t} / \mathrm{ha}$ ). (For interpretation of the references to colour in this figure legend, the reader is referred to the web version of this article.)
Table 6

Estimated rice-yield for threshold, AHZs ( $f 7$ and $f 15)$ and for Babahoyo canton.

\begin{tabular}{lcc}
\hline & NDVI_ave & Expected Yield (tonnes $/$ ha) \\
\hline Threshold & 0.40 & 2.6 \\
$f 7$ & 0.49 & 5.1 \\
$f 15$ & 0.55 & 6.7 \\
Cantonal & 0.51 & 5.7 \\
\hline
\end{tabular}

Table 7

NDVI_ave and historical rice-yield in Babahoyo canton.

\begin{tabular}{llll}
\hline Year & NDVI_ave & Yield (t/ha) & Category \\
\hline 2008 & 0.37 & 2.00 & Years affected by extreme climatic events \\
2012 & 0.40 & 2.57 & \\
2013 & 0.40 & 2.63 & \\
2016 & 0.40 & 2.66 & \\
2017 & 0.42 & 3.07 & Years affected by moderate climatic events \\
2014 & 0.42 & 3.13 & \\
2015 & 0.45 & 3.89 & \\
2010 & 0.46 & 4.19 & \\
2002 & 0.48 & 4.78 & Normal years \\
2005 & 0.49 & 4.89 & \\
2011 & 0.49 & 4.99 & \\
2001 & 0.51 & 5.51 & Years with good climatic conditions \\
2009 & 0.51 & 5.67 & \\
2007 & 0.52 & 5.82 & \\
2003 & 0.54 & 6.40 & \\
2004 & 0.55 & 6.54 & \\
2006 & 0.55 & 6.57 & \\
\hline
\end{tabular}

Table 8

ANOVA for different NDVI sampling densities of agro-ecological homogeneous zones (AHZs) $f 7$ and $f 15$.

\begin{tabular}{lccccc}
\hline Source & Sum of squares & F.D. & Mean square & F-Ratio & P-Value \\
\hline Main effects & & & & & \\
A: sampling density & 0.032 & 5 & 0.0065 & 0.52 & 0.759 \\
B:AHz & 5.80 & 1 & 5.802 & $\mathbf{4 7 0 . 9 6}$ & $\mathbf{0 . 0 0 0}$ \\
Interactions & & & & & \\
AB & 0.092 & 5 & 0.0184 & 1.49 & 0.188 \\
Residues & 1127.50 & 91,520 & 0.0123 & & \\
Total (corrected) & 1136.13 & 91,531 & & &
\end{tabular}

Italic and bold represent significant statistical difference.

Means and LSD (99\%)

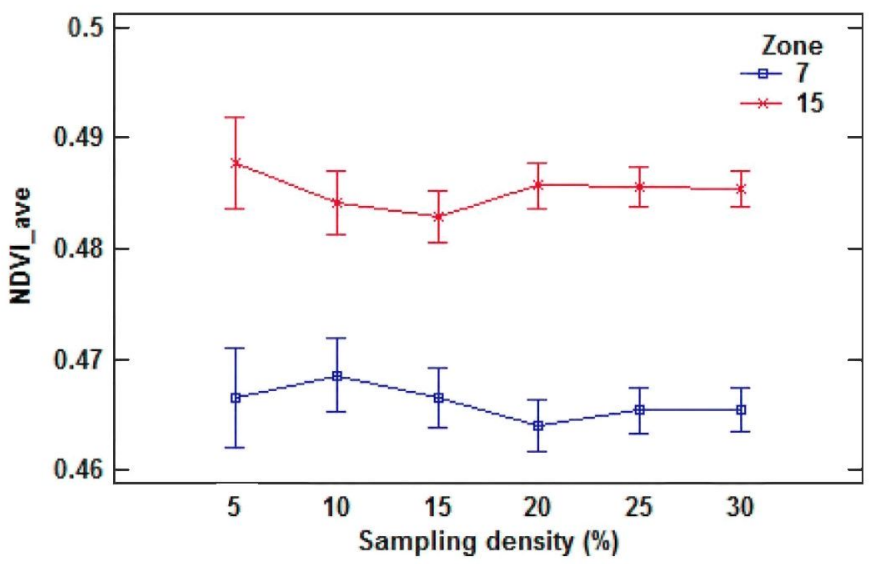

Fig. 7. Multiple rank test (LSD) of NDVI ave means for the interaction between agro-ecological homogeneous zones ( $f 7$ and $f 15)$ and sampling densities. 


\subsection{Effect of soil variability on failure probability in rice crops}

Calculating the percentage of NDVI values under the selected threshold $(t=0.4)$, we have observed that $f 7$ had more events $(25 \%)$ than that of $f 15(17 \%)$ for the analysed 17 years (Fig. 5 C). The Z-test shows that these proportions of accumulated events in each AHZ ( $f 7$ and f15) are significantly different because the calculated $Z$ value (18.06) is outside the critical rate.

As previously mentioned, the different soil characteristics of AHZs $f 7$ and $f 15$ affect the rice crop risk status coping extreme events (drought and flood). The interaction between agro-ecological char-acteristics and these phenomena is clear. $f 7$ is more affected by floods than is $f 15$; due to, $f 7 \mathrm{~s}$ very fine texture ( $>50 \%$ clay), low altitude $(1-12 \mathrm{~m}$ ) and flat topography, hindering the proper drainage, and ac-centuating its flooding vulnerability. On the other hand, under drought conditions, the $f 7$ soil characteristics resulted in better water retention than those of $f 15$, but at the same time, this water is not available easily to crops (Baver et al., 1972). Under extreme drought conditions, the Vertisol soil order (Soil Survey Staff, 2014) becomes difficult to till, presenting deep and wide cracks that can even destroy roots.

\subsection{Sampling density effect}

Several sampling densities for both AHZs were tested showing that there were no significant differences among the 5\% to $30 \%$ densities (Table 8). At any of the tested densities, both AHZs were significantly different. In other words, the difference in NDVI_ave between AHZs $f 7$ and $f 15$ was always statistically significant and discriminated at all sampling densities (Fig. 7). This shows that once the sampling is stratified through AHZs, the NDVI_ave is quite homogeneous within each AHZ, maintaining a statistically significant difference between AHZs ( $f 7$ and $f 15$ ) even at low sampling densities ( 5 or $10 \%$ ).

In practical applications, a representative and accurate NDVI_ave sampling is desirable. Observing Fig. 7, any of the sampling densities provide a stable value for each AHZ. However, 5\% sampling density shows a higher variance than the rest of the sampling densities. Thereby, in the context of IBI, a 10\% sampling density is recommended.

\section{Conclusions}

The differences between the AHZs $f 7$ and $f 15$ were evidenced over bare soil. Statistically significant differences for the reflectance means of $f 7$ and $f 15$ for the red, blue, NIR and MIR bands were found in satellite imagery.

AHZs $f 7$ and $f 15$, which mainly differ in terms of soil, topographic, and climatic characteristics, have an influence in the response of rice crop growth. This effect has been detected over the NDVI average of the rice crop cycle (NDVI_ave), and significant differences in the NDVI_ave of AHZ $f 7$ and $f 15$ were found.

The percentage of values below the NDVI_ave threshold of 0.4 , related to rice crop failure, in AHZs $f 7$ and $f 15$ are statistically significantly different: $25 \%$ and $17 \%$, respectively. These results clearly show a higher crop failure probability in $f 7$ than in $f 15$. In the context of IBI implementation, it is necessary to adjust the premium price for each AHZ; otherwise, insurance would not be sustainable as the $f 15$ farmers will eventually leave.

Significant differences among sampling densities were not found because of the very low intra-variability of AHZ and the high AHZs inter-variability. In other words, NDVI_ave is quite homogeneous inside each AHZ and very different between AHZs $f 7$ and $f 15$. For practical purposes in IBI implementation, a $10 \%$ sampling density is recommended, as it presents adequate accuracy and representativeness, as it was found in this study.

\section{Acknowledgements}

Financial support for Omar Valverde Ph.D. studies in the UPM by National Secretary of Higher Education Science Technology and Innovation of Ecuador (SENESCYT in Spanish) is greatly appreciated. The authors would like to also acknowledge to CGSIN-MAGAP for the data provided.

\section{References}

Arias, O.V., Garrido, A., Villeta, M., Tarquis, A.M., 2018. Homogenisation of a soil properties map by principal component analysis to define index agricultural in surance policies. Geoderma 311, 149-158. https://doi.org/10.1016/j.geoderma. 2017.01.018.

Barnes, E.M., Baker, M.G., 2000. Multispectral data for mapping soil texture: possibilities and limitations. Appl. Eng. Agric. 16, 731. https://doi.org/10.13031/2013.5370.

Barraza, K.B., 2012. Estrategias innovadoras para la gestión del riesgo de sequía es sistemas ganaderos extensivos. Universidad Politécnica de Madrid.

Barrett, C.B., Carter, M.R., Chantarat, S., McPeak, J., Mude, A.G., 2008. Altering Poverty Dynamics with Index Insurance: Northern Kenya's HSNP. B ASIS Br.

Baver, L.D., Gardner, W.H., Gardner, W.R., 1972. Soil Physics. John Wiley \& Sons Ltd, New York.

Binswanger-Mkhize, H.P., 2012. Is there too much hype about index-based agricultural insurance? J. Dev. Stud. 48, 187-200.

Cabangon, R.J., Tuong, T.P., 2000. Management of cracked soils for water saving during land preparation for rice cultivation. Soil Tillage Res. 56, 105-116. https://doi.org/ 10.1016/S0167-1987(00)00125-2.

Cambardella, C.A., Moorman, T.B., Parkin, T.B., Karlen, D.L., Novak, J.M., Turco, R.F., Konopka, A.E., 1994. Field-scale variability of soil properties in Central Iowa soils. Soil Sci. Soc. Am. J. 58, 1501-1511. https://doi.org/10.2136/sssaj1994. $03615995005800050033 x$.

Chantarat, S., Barrett, C.B., Mude, A.G., Turvey, G.G., 2007. Using weather index insurance to improve drought response for famine prevention. Am. J. Agric. Econ. 89 1262-1268. https://doi.org/10.1111/j.1467-8276.2007.01094.x.

Clarke, D.J., 2016. A theory of rational demand for index insurance. Am. Econ. J. Microecon. 8, 283-306. https://doi.org/10.1257/mic.20140103.

Didan, K, 2015. MOD13Q1 MODIS/Terra Vegetation Indices 16-day L3 Global $250 \mathrm{~m}$ SIN Grid V006. NASA EOSDIS Land Processes DAAChttps://doi.org/10.5067/MODIS/ MOD13Q1.006.

Didan, K., Barreto, A., Solano, R., Huete, A., 2015. MODIS Vegetation Index User's Guide (MOD13 Series) Version 3.00. (Collection 6).

Gomez, C., Rossel, R.A.V., McBratney, A.B., 2008. Soil organic carbon prediction by hyperspectral remote sensing and field Vis-NIR spectroscopy: an Australian case study. Geoderma 146, 403-411.

Gu, Y., Brown, J.F., Verdin, J.P., Wardlow, B., 2007. A five year analysis of MODIS NDVI and NDWI for grassland drought assessment over the central Great Plains of the United States. Geophys. Res. Lett. 34.

Gu, Y., Wylie, B.K., Howard, D.M., Phuyal, K.P., Ji, L., 2013. NDVI saturation adjustment: a new approach for improving cropland performance estimates in the greater Platte River basin, USA. Ecol. Indic. 30, 1-6. https://doi.org/10.1016/j.ecolind.2013.01. 041.

Hegerl, G.C., Zwiers, F.W., Braconnot, P., Gillett, N.P., Luo, Y., Marengo Orsini, J.A., Nicholls, N., Penner, J.E., Stott, P.A., 2007. Understanding and Attributing Climate Change.

Seguros en base a índices climáticos y riesgo climático: Perspectivas para el desarrollo y la gestión de desastres. In: Hellmuth, M., Osgoog, D., Hess, U., Moorhead, A., Bhojwani, H. (Eds.), Clima y Sociedad No. 2. Instituto Internacional de Investigación para el Clima y la Sociedad (IRI), The Earth Institute at Columbia University, Nueva YorkEEUU.

Henderson, T.L., Baumgardner, M.F., Franzmeier, D.P., Stott, D.E., Coster, D.C., 1992. High dimensional reflectance analysis of soil organic matter. Soil Sci. Soc. Am. J. 56, 865-872. https://doi.org/10.2136/sssaj1992.03615995005600030031x.

Hertzler, G., 2004. Weather derivatives and yield index insurance as exotic options. In: 48th Conference of the Australian Agricultural and Resource Economics Society, Melbourne, (February).

Huang, J., Wang, X., Li, X., Tian, H., Pan, Z., 2013. Remotely sensed rice yield prediction using multi-temporal NDVI data derived from NOAA's-AVHRR. PLoS One 8, e70816.

IEE-Instituto Espacial Ecuatoriano, 2009. Technical Report of Production Systems in Babahoyo Canton. Quito-Ecuador.

Krishnan, P., Alexander, J.D., Butler, B.J., Hummel, J.W., 1980. Reflectance technique for predicting soil organic matter 1. Soil Sci. Soc. Am. J. 44, 1282-1285. https://doi.org/ 10.2136 /sssaj 1980.03615995004400060030x.

de Leeuw, J., Vrieling, A., Shee, A., Atzberger, C., Hadgu, K.M., Biradar, C.M., Keah, H. Turvey, C., 2014. The potential and uptake of remote sensing in insurance: a review. Remote Sens. 6, 10888-10912.

Letey, J., 1985. Relationship between soil physical properties and crop production. In: Stewart, B.A. (Ed.), Advances in Soil Science. Springer New York, New York, NY, pp. 277-294. https://doi.org/10.1007/978-1-4612-5046-3_8.

MAGAP-Ministerio de Agricultura Ganaderia Acuacultura y Pesca, 2014. Map of Estimated Area of Rice and Maize Cultivation in the Provinces of Guayas, Santa Elena, Los Rios, Manabí, El Oro and Loja in 2014 [WWW Document]. Geoportal del Agro Ecuatoriano URL. http://geoportal.agricultura.gob.ec/catalogo_datos/ visualizador.html. 
Menand, L., Townsend, R., 2010. Microinsurance: a case study of the Indian rainfall indexinsurance market. World Bank, pp. 49.

Mobarak, A.M., Rosenzweig, M.R., 2013. Informal risk sharing, index insurance, and taking in developing countries. Am. Econ. Rev. 103, 375-380.

Moreno, B., 2014. Yield Rice in Ecuador. First Quarter 2014. Quito-Ecuador.

Mouazen, A.M., Karoui, R., De Baerdemaeker, J., Ramon, H., 2005. Classification of soil texture classes by using soil visual near infrared spectroscopy and factorial discriminant analysis techniques. J. Near Infrared Spectrosc. 13, 231-240. https://doi. $\operatorname{org} / 10.1255 /$ jnirs.541.

Mude, A., Barrett, C.B., Carter, M.R., Chantarat, S., Ikegami, M., McPeak, J.G., 2009 Index Based Livestock Insurance for Northern Kenya's Arid and Semi-arid Lands: The Marsabit Pilot. (Available SSRN 1844758).

NASA LP DAAC, 2015. MOD1301: MODIS/Terra Vegetation Indices 16-day L3 Global $250 \mathrm{~m}$ Grid SIN V006 [WWW Document]. USGS Earth Resour. Obs. Sci. Center, Sioux Falls, South Dakota. https://doi.org/10.5067/MODIS/MOD13Q1.006.

Pettorelli, N., Vik, J.O., Mysterud, A., Gaillard, J.-M., Tucker, C.J., Stenseth, N.C., 2005. Using the satellite-derived NDVI to assess ecological responses to environmental change. Trends Ecol. Evol. 20, 503-510. https://doi.org/10.1016/j.tree.2005.05. 011.

Polasek, W., 2013. Multivariate analysis for the biobehavioral and social sciences: a graphical approach by Bruce L. Brown, Suzanne B. Hendrix, Dawson W. Hedges, Timothy B. Smith. Int. Stat. Rev. 81, 463-465. https://doi.org/10.1111/insr. 12042 . 5 .

Quarmby, N.A., Milnes, M., Hindel, T.L., Sileos, N., 1993. The use of multi-temporal NDVI measurements from AVHRR data for crop yield estimation and prediction. Int. J. Remote Sens. 14, 199-210. https://doi.org/10.1080/01431169308904332.

Rondeaux, G., Steven, M., Baret, F., 1996. Optimization of soil-adjusted vegetation in dices. Remote Sens. Environ. 55, 95-107. https://doi.org/10.1016/0034-4257(95) 00186-7.

Rulinda, C.M., Dilo, A., Bijker, W., Stein, A., 2012. Characterising and quantifying vegetative drought in East Africa using fuzzy modelling and NDVI data. J. Arid Environ. 78, 169-178. https://doi.org/10.1016/j.jaridenv.2011.11.016.

Sivakumar, M., Motha, R., Das, H., 2005. Natural Disasters and Extreme Events in Agriculture. Impacts and Mitigation. Springer, Berlin, Heidelberg, Berlin. https://doi. org/10.1007/3-540-28307-2

Skees, J.R., Hartell, J., Murphy, A.G., 2007. Using index-based risk transfer products to facilitate micro lending in Peru and Vietnam. Am. J. Agric. Econ. 89, 1255-1261.

Soil Survey Staff, 2014. Keys to Soil Taxonomy, 12th ed. USDA-Natural Resources Conservation Service, Washington, DC.

Son, N.T., Chen, C.F., Chen, C.R., Chang, L.Y., Minh, V.Q., 2012. Monitoring agricultural drought in the lower Mekong Basin using \{MODIS\} \{NDVI\} and land surface temperature data. Int. J. Appl. Earth Obs. Geoinf. 18, 417-427. https://doi.org/10.1016/ j.jag.2012.03.014.

Son, N.T., Chen, C.F., Chen, C.R., Minh, V.Q., Trung, N.H., 2014. A comparative analysis of multitemporal MODIS EVI and NDVI data for large-scale rice yield estimation. Agric. For. Meteorol. 197, 52-64. https://doi.org/10.1016/j.agrformet.2014.06.007.

Stoppa, A., Hess, U., 2003. Design and use of weather derivatives in agricultural policies: the case of rainfall index insurance in Morocco. In: Int. Conf. Agric. Policy Reform WTO Where Are We Head, pp. 23-26.

Subash, N., Ram Mohan, H.S., Banukumar, K., 2011. Comparing water-vegetative indices for rice (Oryza sativa L.)-wheat (Triticum aestivum L.) drought assessment. Comput. Electron. Agric. 77, 175-187. https://doi.org/10.1016/j.compag.2011.05.001.

Thomasson, J.A., Sui, R., Cox, M.S., Al-Rajehy, A., 2001. Soil reflectance sensing for determining soil properties in precision agriculture. Trans. ASAE 44, 1445.

Trærup, S.L.M., 2012. Informal networks and resilience to climate change impacts: a collective approach to index insurance. Glob. Environ. Chang. 22, 255-267. https:// doi.org/10.1016/j.gloenvcha.2011.09.017.

Trangmar, B.B., Yost, R.S., Uehara, G., 1986. In: Brady, N.C.B.T.-A. (Ed.), Application of Geostatistics to Spatial Studies of Soil Properties. Academic Press, pp. 45-94. https:// doi.org/10.1016/S0065-2113(08)60673-2.

Valverde-Arias, O., Garrido, A., Valencia, J.L., Tarquis, A.M., 2018. Using geographical information system to generate a drought risk map for rice cultivation: case study in Babahoyo canton (Ecuador). Biosyst. Eng. 168, 26-41. https://doi.org/10.1016/j. biosystemseng.2017.08.007.

Viscarra Rossel, R.A., Walvoort, D.J.J., McBratney, A.B., Janik, L.J., Skjemstad, J.O., 2006. Visible, near infrared, mid infrared or combined diffuse reflectance spectroscopy for simultaneous assessment of various soil properties. Geoderma 131, 59-75. https://doi.org/10.1016/j.geoderma.2005.03.007.

Weidong, L., Baret, F., Xingfa, G., Qingxi, T., Lanfen, Z., Bing, Z., 2002. Relating soil surface moisture to reflectance. Remote Sens. Environ. 81, 238-246.

White, D., Kimerling, J.A., Overton, S.W., 1992. Cartographic and geometric components of a global sampling design for environmental monitoring. Cartogr. Geogr. Inf. Syst. 19, 5-22. https://doi.org/10.1559/152304092783786636.

Williams, L.J., Abdi, H., 2010. Fisher's least significant difference (LSD) test. Encycl. Res. Des. 218, 840-853.

Wright, B.D., Hewitt, J.A., 1994. All-risk crop insurance: lessons from theory and experience. In: Huett, D.L., Furtan, W.H. (Eds.), Economics of Agricultural Crop Insurance: Theory and Evidence. Springer, Dordrecht. https://doi.org/10.1007/97894-011-1386-1_4. 